\title{
GnRH-ASSOCIATED PEPTIDE (GAP) IS COSECRETED WITH GnRH INTO THE HYPOPHYSEAL PORTAL BLOOD OF OVARIECTOMIZED SHEEP ${ }^{1}$
}

\author{
I.J. Clarke ${ }^{2}$, J.T. Cummins ${ }^{2,3}$, F.J. Karsch ${ }^{2,4}$, P.H. Seeburg, and K. Nikolics ${ }^{5}$ \\ ${ }^{2}$ Medical Research Centre, Prince Henry's Hospital, St. Kilda Rd, \\ Melbourne, 3004, Australia \\ $3^{3}$ Department of Neurosurgery, St. Vincent's Hospital, Fitzroy, \\ Melbourne, Australia \\ ${ }^{4}$ Reproductive Endocrinology Program, University of Michigan, \\ Ann Arbor, Michigan \\ ${ }^{5}$ Department of Developmental Biology, Genentech, Inc., \\ South San Francisco, California 94080
}

Received January 21, 1987

SUMMARY: The secretion of gonadotropin-releasing hormone (GnRH) and GnRH-associated peptide (GAP) into sheep hypothalamo-hypophyseal portal blood was investigated in ovariectomized ewes. GAP and GnRH were cosecreted into portal blood as determined in pooled 'peak' and 'trough' samples. The temporal pattern of GAP secretion into portal blood was coincidental with that of luteinizing hormone (LH) secretion into peripheral blood in three individual animals. The data provide the first evidence that GAP is a secretory product from mammalian hypothalamus and establish the temporal coexistence of the two peptides which appears to be of physiological significance in the regulation of pituitary function.

tcic 1987 Academic Press, Ine.

Hypothalamic peptides which regulate various pituitary functions are synthesized in neurosecretory cells and released periodically from nerve terminals into the hypothalamo-pituitary portal circulation [1]. Gonadotropin-releasing hormone (GnRH or LHRH) is secreted in a pulsatile pattern into hypophyseal portal blood which, in turn, results in the pulsatile secretion of luteinizing hormone (LH) into the peripheral circulation $[2,3]$.

$\mathrm{GnRH}$ is synthesized as part of a precursor protein which also contains GAP, the 56 amino acid GnRH-associated peptide suggested to participate in the regulation of

\footnotetext{
1 Presented in part at the 68th Annual Meeting of the Endocrine Society, Anaheim, June, 1986.
} 
prolactin and gonadotropin secretion [4-6]. Antisera raised against synthetic peptides representing different structural regions of GAP were used to reveal the presence of immunoassayable GAP-related antigen in rat hypothalamus [7]. Immunocytochemical staining of rat brain showed that GAP is present in the same neurosecretory cells, axons and nerve terminals which contain GnRH. Furthermore, GAP immunostaining in dense-cored vesicles of terminal varicosities within the median eminence suggested that GAP could be secreted into the portal circulation [7].

In this study we evaluated GnRH and GAP levels in portal blood and correlated the temporal pattern of GAP in portal circulation with that of LH in peripheral circulation using a previously described sheep model which uniquely allows simultaneous sampling at both levels $[3,8]$.

\section{MATERIALS AND METHODS}

Animals, Surgery and Sampling Procedure

Mature corriedale ewes were used within 7-8 days of ovariectomy in Experiment 1 or more than one month after ovariectomy in Experiment 2. The sheep were prepared for the sampling of portal blood under anesthesia as previously outlined [3,8]. Portal and jugular venous blood samples were collected 1-2 days after surgery.

On the day prior to portal sampling, one jugular vein was catheterized; this catheter was subsequently used to collect blood samples for LH analysis. On the day of portal blood sampling the sheep were given 25,000 units of heparin (CSL, Melbourne) at $0700 \mathrm{~h}, 0800 \mathrm{~h}, 0900 \mathrm{~h}$ and every $2 \mathrm{~h}$ subsequently. In addition the sheep received an infusion of heparin via the jugular catheter $(75,000$ units/liter saline over 6-8 h). At $0900 \mathrm{~h}$ the hypophyseal portal vessels on the anterior face of the pituitary gland were stabbed and the resultant portal blood was collected as previously described $[3,8]$. Paired samples of portal blood $(\sim 2 \mathrm{ml})$ and jugular blood $(\sim 6 \mathrm{ml})$ were collected each 5-10 min for a period of 6-7 $\mathrm{h}$.

Experiment 1: In 5 sheep portal samples and jugular samples were collected into ice-cold $0.5 \mathrm{ml} 5 \mathrm{mM}$ bacitracin (Sigma, St. Louis). All samples were centrifuged at $4^{\circ} \mathrm{C}$ and plasma stored at $-15^{\circ} \mathrm{C}$. The portal samples were assayed for $\mathrm{GnRH}$ and the peripheral samples for LH. After the secretory profile of GnRH had been established all 'peak and 'trough' samples were pooled for each animal. Aliquots of these pooled samples were reassayed for GnRH with the exception of sheep 447, refrozen, transported on dry-ice from Melbourne to San Francisco and assayed for GAP. Experiment 2: In another series of experiments three long-term (1 month) ovariectomized ewes were sampled as described above. The portal samples and the appropriate jugular control samples were assayed for GAP and the peripheral samples were assayed for LH.

\section{Assays}

Plasma LH and GnRH were measured by established methods as described previously $[3,8,9]$. For the LH assay NIH-LH-S18 was used as standard and the asays had a sensitivity of $21-86 \mathrm{pg} / \mathrm{ml}$; between assay coefficients of variation were $<15 \%$. For GnRH a modification of the original protocol was used. Assay sensitivity was $0.2 \mathrm{pg} /$ tube and between assay c.v. was $11.2 \%$ at $23.1 \pm 2.6 \mathrm{pg} / \mathrm{ml}$ and $15.1 \%$ at $13.2 \pm$ $2.0 \mathrm{pg} / \mathrm{ml}$.

For the GAP radioimmunoassays antisera $24 \mathrm{~A}, 56 \mathrm{~A}$ and $\mathrm{KN}-1$ were used which were raised against $B S A$ conjugates of rat GAP-(1-11), rat GAP-(20-43) and rat 
GAP-(39-53), respectively [9]. RIAs were developed using the corresponding synthetic peptides as standards and their respective p-hydroxyphenyl-maleimide derivatives for radioiodination which was carried out in the presence of chloramine-T [10]. The antisera were used in dilutions of $1: 12,000 ; 1: 24,000$; and 1:8,000 respectively. Samples or standards, tracer and antiserum were made up in phosphate buffered saline pH 7.5 containing $0.01 \% \mathrm{NaN}_{3}, 0.02 \mathrm{M}$ EDTA and $0.5 \%$ BSA (Sigma, St. Louis; fraction V for RIA). The second antibody (goat anti-rabbit serum, Antibodies Incorporated, Davis) and nonimmune rabbit serum (EL Laboratories, Soquel) were made up in $0.05 \mathrm{M}$ phosphate, pH 7.5 containing $0.5 \%$ BSA (buffer B). To $400 \mu \mathrm{l}$ sample or standard $50 \mu \mathrm{l}$ antiserum was added and incubated for 6-10 h at room temperature. Then $50 \mu \mathrm{l}$ tracer $(\sim 12,000 \mathrm{cpm})$ was added and the mixture further incubated for 10-12 hours. Then $50 \mu \mathrm{l}$ second antibody (1:20 dilution) and $50 \mu \mathrm{l}$ rabbit serum (1:50 dilution) were added and the tubes further incubated for $12-16 \mathrm{~h}$ at room temperature. After the addition of $0.6 \mathrm{ml}$ ice-cold buffer $\mathrm{B}$ the tubes were centrifuged for $30 \mathrm{~min}$ at $3,000 \mathrm{rpm}$ at $4^{\circ} \mathrm{C}$ and the resultant pellets were counted. For the construction of standard curves peripheral plasma was added to the corresponding tubes. The different GAP assay sensitivities were 5.2 $\mathrm{pg} /$ tube with antiserum $24 \AA, 3.0 \mathrm{pg} /$ tube with antiserum $56 \mathrm{~A}$ and $7.1 \mathrm{pg} /$ tube with antiserum $\mathrm{KN}-1$.

\section{RESULTS AND DISCUSSION}

The typical temporal pattern of GnRH secretion into portal blood and LH release into the peripheral circulation is shown in Fig. 1 (Experiment 1). Periodicity of "peaks" and "troughs" of the two hormones shows very good correlation as described earlier $[3,8]$. In four animals the concentration of GAP was measured by radioimmunoassay in pools of portal blood samples which had been pooled on the

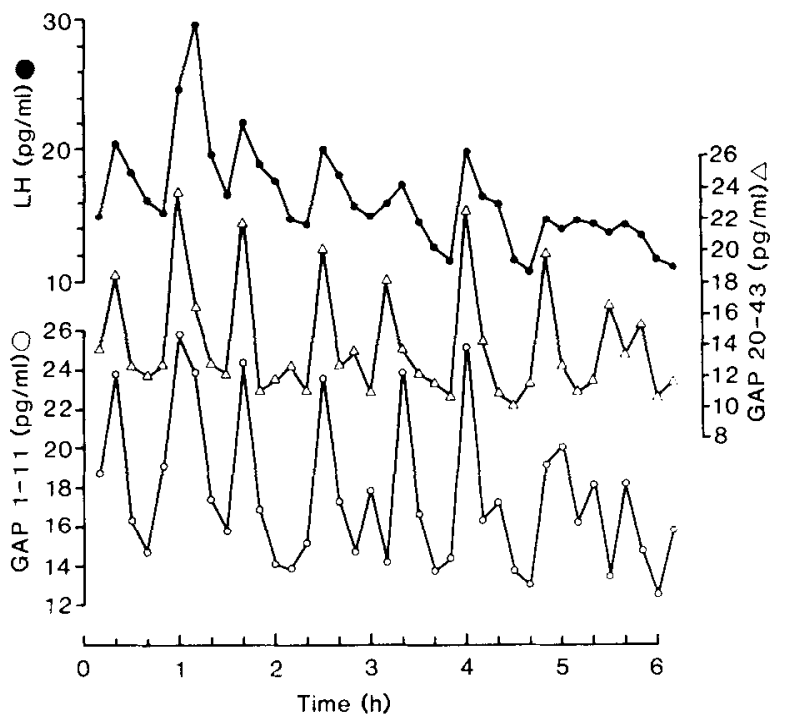

Fig. 1. Concentrations of GnRH in hypothalamo-hypophyseal portal plasma and LH in jugular venous (peripheral) plasma of one ovariectomized sheep. The GnRH samples indicated as closed circles were pooled as 'peaks' and those indicated as open circles were pooled as 'troughs'. 
Table 1

Concentrations of GnRH and GAP in pooled samples from four ovariectomized ewes

\begin{tabular}{|c|c|c|c|c|}
\hline \multirow[b]{2}{*}{ Peptide } & \multicolumn{2}{|c|}{ "Peak" } & \multicolumn{2}{|c|}{ "Trough" } \\
\hline & $\overline{\mathrm{GnRH}}$ & GAP & GnRH & GAP \\
\hline Sheep 45 & 14.9 & 27.8 & 1.3 & $<7.0$ \\
\hline Sheep 447 & n.d. & 24.7 & n.d & $<7.0$ \\
\hline Sheep 245 & 12.3 & 30.4 & 1.4 & 8.5 \\
\hline Sheep 468 & 6.0 & 21.1 & $<0.3$ & $<7.0$ \\
\hline \multicolumn{5}{|c|}{$\begin{array}{l}\text { For each sheep "peaks" and "troughs" were pooled based on GnRH levels } \\
\text { determined by RIA as shown in Fig.1. For sheep } 447 \text { there was insufficient pooled } \\
\text { sample to reassay for GnRH (n.d., not determined in reassay). Values are expressed } \\
\text { in } \mathrm{pg} / \mathrm{ml} \text {. }\end{array}$} \\
\hline
\end{tabular}

basis of GnRH "peaks" and "troughs" as indicated in Fig. 1. Data in Table 1 show that in each animal the peak samples, in relation to trough samples, contained greatly elevated levels of both peptides demonstrating that GnRH and GAP were cosecreted from the hypothalamus as expected from their sharing the same biosynthetic precursor protein [4-6]. The molar ratios of GnRH to GAP varied between 1:0.35 to 1:0.65 in peak samples. These values are in the same order of magnitude but diverge somewhat from the expected 1:1 ratio. The lower values for GAP can be due to several reasons, amongst which probably the most important is the unknown crossreactivity of sheep GAP with antisera to synthetic peptides corresponding to rat GAP used in these assays. Human and rat GAP share a sequence homology of approximately $70 \%$ [6]. Sequence variations between the two peptides are mostly in the N-terminal region, some in the middle and C-terminal regions and thus species differences can be expected to exist between rat and sheep GAP. It is also possible that the half-lives of the two peptides are different in serum. The antibodies utilized in these studies recognized GAP within the prohormonal form [7] and therefore, we cannot exclude the possibility that some unprocessed prohormone is also secreted into portal blood. However, earlier studies using antisera recognizing GnRH only in its mature form (blocked termini) suggested that 

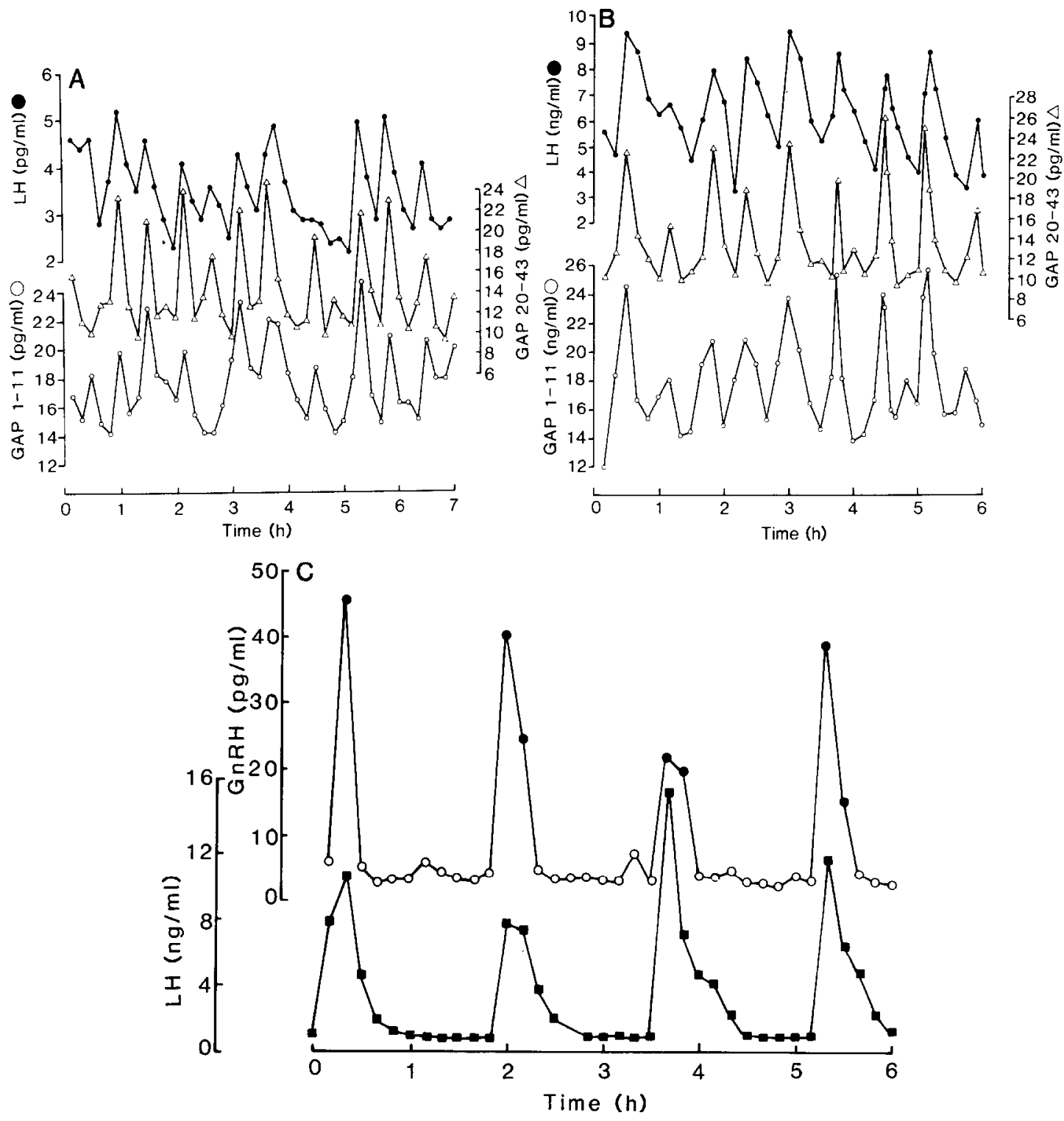

Fig. 2. Concentrations of GAP in portal plasma and LH in jugular plasma of three ovariectomized sheep (A, B, C). GAP was determined by the $\mathrm{N}$-terminal (1-11, AS $24 \mathrm{~A}$ ) and middle (20-43, AS 56A) GAP radioimmunoassays and values are expressed in $\mathrm{pg} / \mathrm{ml}$ portal plasma. Values for $\mathrm{LH}$ are expressed in $\mathrm{ng} / \mathrm{ml}$ peripheral plasma.

processing of the prohormone proceeds to completion before secretion in the median eminence [11].

The temporal pattern of GAP in portal blood was investigated in three ovariectomized ewes (Experiment 2). Fig. 2 shows GAP concentrations in portal blood sampled at 5-10 min intervals over the course of a 6-7 hour period using radioimmunoassays based on antibodies against the $\mathrm{N}$-terminus and the middle part 
of rat GAP. Results with both antibodies show excellent agreement and demonstrate that GAP was secreted into the portal circulation in the same pulsatile fashion as GnRH.

Since LH concentration in peripheral blood has been found to be a very good indicator of GnRH output from the hypothalamus, portal plasma GAP levels in these three animals were compared with peripheral plasma LH levels as shown in Fig. 2. Very good correlation was seen between pulses of GAP in portal blood and pulses of LH in simultaneously sampled peripheral blood, again demonstrating the close temporal relationship between the hypothalamic secretion of peptides that originate from the GnRH-GAP precursor and pituitary release of gonadotropins. The coexistence of the two peptides in portal blood and their simultaneous transport to the anterior pituitary could be of great significance in the coordinate control of pituitary gonadotropin and prolactin secretion [5].

The results of these experiments show for the first time the presence of GAP in hypophyseal portal blood and demonstrate that this peptide is released in an episodic fashion identical to GnRH. This is in good agreement with previous analysis of the GnRH gene and its product, the GnRH-GAP precursor. GAP is a peptide of 56 amino acids which contains several basic residues and has a pair of lysyl residues at its $C$ terminus. Even though the results presented in these studies suggest that the whole 56-amino acid form of GAP is the final processed and secreted form, we cannot exclude the possibility that GAP undergoes further processing to smaller peptides which might carry differential regulatory activity at the pituitary level. Our finding that antisera raised against $\mathrm{N}$-terminus, middle part and C-terminus (data not shown) of GAP detect antigen in portal blood would argue against this possibility, as did the previous finding of high in vitro hypophyseotropic activity of the whole GAP molecule on pituitary cells [5]. The isolation and characterization of GAP and its potential processed fragments from hypothalamic tissue will provide answers to this question.

ACKNOWLEDGEMENTS: We thank Lynda Cavanagh, Kathy Burman, Bruce Doughton, Paul Weston and Trevor Gill for assistance in the animal experiments and the Director of the Victorian Department of Agriculture Animal Research 
Institute, Werribee for the use of facilities. We thank Dr. John Burnier and Martin Struble for synthetic peptides. This work was supported by the National Health and Medical Research Council of Australia and Genentech, Inc.

\section{REFERENCES}

1. Reichlin, S. (1985) in: Textbook of Endocrinology, Eds. Wilson, J.D. and Foster, D.W., W.B. Saunders Co., Philadelphia, pp. 492-567

2. Carmel, P.W., Araki, S., and Ferin, M. (1976) Endocrinology 99, 243-250

3. Clarke, I.J. and Cummins, J.T. (1982) Endocrinology 111, 1737-1739

4. Seeburg, P.H. and Adelman, J.P. (1984) Nature (London) $\underline{311}$ 666-668

5. Nikolics, K., Mason, A.J., Szonyi, E., Ramachandran, J. and Seeburg, P.H. (1985) Nature (London) 316, 511-517

6. Adelman, J.P., Mason, A.J., Hayflick, J.S. and Seeburg, P.H. (1986) Proc. Natl. Acad. Sci. USA $83,179-183$

7. Phillips, H.S., Nikolics, K., Branton, D. and Seeburg, P.H. (1985) Nature (London) 316, 542-545

8. Clarke, I.J., Cummins, J.T., Findlay, J.K., Burman, K.J. and Doughton, B.W. (1984) Neuroendocrinology $\underline{39}, 214-221$

9. Nikolics, K. and Seeburg P.H. (1986) In: Neuroendocrine Molecular Biology, Eds. Fink, G., Harmar, A.J. and McKerns, K.W., Plenum Press., New York, pp. 57-65

11. Hunter, W.M. and Greenwood, F.C. (1962) Nature (London) 194, 495-497

12. King, J.C. and Anthony, E.L.P. (1983) Peptides 4 963-970 